\title{
Growth after late-preterm birth and adult cognitive, academic, and mental health outcomes
}

\author{
Sara Sammallahti ${ }^{1,2,3}$, Kati Heinonen', Sture Andersson ${ }^{2}$, Marius Lahti ${ }^{1,4}$, Sami Pirkola ${ }^{3,5}$, Jari Lahti ${ }^{1,6}$, Anu-Katriina Pesonen', \\ Aulikki Lano' ${ }^{2}$, Dieter Wolke', Johan G. Eriksson ${ }^{3,8,9,10}$, Eero Kajantie ${ }^{2,3,11}$ and Katri Raikkonen ${ }^{1}$
}

BACKGROUND: Late-preterm birth (at 34/7-36/7 wk gestation) increases the risk of early growth faltering, poorer neurocognitive functioning, and lower socio-economic attainment. Among early-preterm individuals, faster early growth benefits neurodevelopment, but it remains unknown whether these benefits extend to late-preterm individuals.

METHODS: In 108 late-preterm individuals, we examined if weight, head, or length growth between birth, 5 and 20 months' corrected age, and $56 \mathrm{mo}$, predicted grade point average and special education in comprehensive school, or neurocognitive abilities and psychiatric diagnoses/symptoms at 24-26 y of age.

RESULTS: For every 1 SD faster weight and head growth from birth to $5 \mathrm{mo}$, and head growth from 5 to $20 \mathrm{mo}$, participants had 0.19-0.41 SD units higher IQ, executive functioning score, and grade point average ( $95 \%$ confidence intervals (CI) $0.002-$ $0.59 \mathrm{SD}$ ), and lower odds of special education (odds ratio (OR) $=0.49-0.59,95 \%$ Cls 0.28-0.97), after adjusting for sex, gestational age, follow-up age, and parental education. Faster head growth from 20 to 56 mo was associated with less internalizing problems; otherwise we found no consistent associations with mental health outcomes.

CONCLUSION: Faster growth during the critical early period after late-preterm birth is associated with better adult neurocognitive functioning, but not consistently with mental health outcomes.

D ecreasing the burden of preterm birth is a public health priority (1). Of the nearly 15 million infants worldwide who are born preterm ( $<37 \mathrm{wk}$ gestation) each year (2), over $70 \%$ are born late-preterm (between $34+0$ and $36+6 \mathrm{wk}+$ days' gestation) (3). The late-preterm infant is faced with a substantial risk of morbidity and mortality compared with term-born peers (4), including an increased risk of early growth faltering (5) and poorer long-term neurocognitive functioning (6) and socio-economic attainment (7). Yet, a large proportion of latepreterm individuals come to cope well, and the risk of mental disorders, for example, seems to be similar for late-preterm and term-born individuals (8).

Even though faster growth in infancy and childhood has been shown to benefit neurodevelopment in those born very preterm $(<32 \mathrm{wk})(9-12)$, early preterm $(<33 \mathrm{wk})(13)$, preterm (14), and preterm with extremely low $(<1,000 \mathrm{~g})(15-18)$ or very low $(<1,500 \mathrm{~g})(9,10,19-22)$ birth weight, in some, though not in all studies (23-25), it still remains unknown if faster early growth also benefits neurodevelopment in those born late-preterm. Accordingly, we examined if growth after late-preterm birth predicts neurocognitive functioning, academic performance, or mental health in individuals who were born late-preterm, and who participated in follow-up examinations at 5 and 20 mo of corrected age (CA) and 56 mo and $25 \mathrm{y}$ of age.

\section{METHODS \\ Participants}

The Arvo Ylppö Longitudinal Study cohort members were recruited from births in the Uusimaa region, Finland, between 15 March 1985 and 14 March 1986. Originally, we prospectively recruited infants who were admitted to a neonatal ward within $10 \mathrm{~d}$ of birth, and for every two hospitalized infants, we also recruited one newborn that did not require hospitalization. This cohort of 2,193 infants, described previously in more detail (8), included 315 late-preterm infants. At 5,20 , and $56 \mathrm{mo}, 277,274$, and 227 late-preterm individuals, respectively, participated in follow-up examinations, including anthropometric measurements.

In 2009-2012, we invited the still traceable 270 late-preterm individuals, who were living within southern Finland to a follow-up: 158 participated $(58.5 \%$ of those invited and $50.2 \%$ of original participants) (Figure 1). We excluded those with intellectual developmental disability $(n=4)$, congenital malformations or chromosomal abnormalities $(n=4)$, or no available data on birth or childhood anthropometry $(n=5)$, precise gestational age $(n=34)$, or adult cognitive, school, or psychiatric data $(n=3)$, resulting in an analytic sample of 108 late-preterm-born adults (mean age 25.2, standard deviation $(S D)=0.6$, range 24.5-26.7 y). The number of participants included

\footnotetext{
'Department of Psychology and Logopedics, University of Helsinki, Helsinki, Finland; ${ }^{2}$ Children's Hospital, Helsinki University Hospital and University of Helsinki, Helsinki, Finland; ${ }^{3}$ National Institute for Health and Welfare, Helsinki, Finland; ${ }^{4}$ University BHF Centre for Cardiovascular Sciences, Queen's Medical Research Institute, University of Edinburgh, Edinburgh, UK; ${ }^{5} \mathrm{School}$ of Health Sciences, University of Tampere and Tampere University Hospital, Tampere, Finland; ${ }^{6} \mathrm{Helsinki}$ Collegium for Advanced Studies, Helsinki, Finland; ${ }^{7}$ Department of Psychology, University of Warwick, Coventry, UK; ${ }^{8}$ Folkhälsan Research Center, Helsinki, Finland; ${ }^{9}$ Department of General Practice and Primary Health Care, University of Helsinki and Helsinki University Hospital, Helsinki, Finland; ${ }^{10}$ Vasa Central Hospital, Vasa, Finland; ${ }^{11}$ Department of Obstetrics and Gynecology, Oulu University Hospital and University of Oulu, Oulu, Finland. Correspondence: Sara Sammallahti (sara.sammallahti@helsinki.fi) 


\section{Articles $\mid$ Sammallahti et al.}

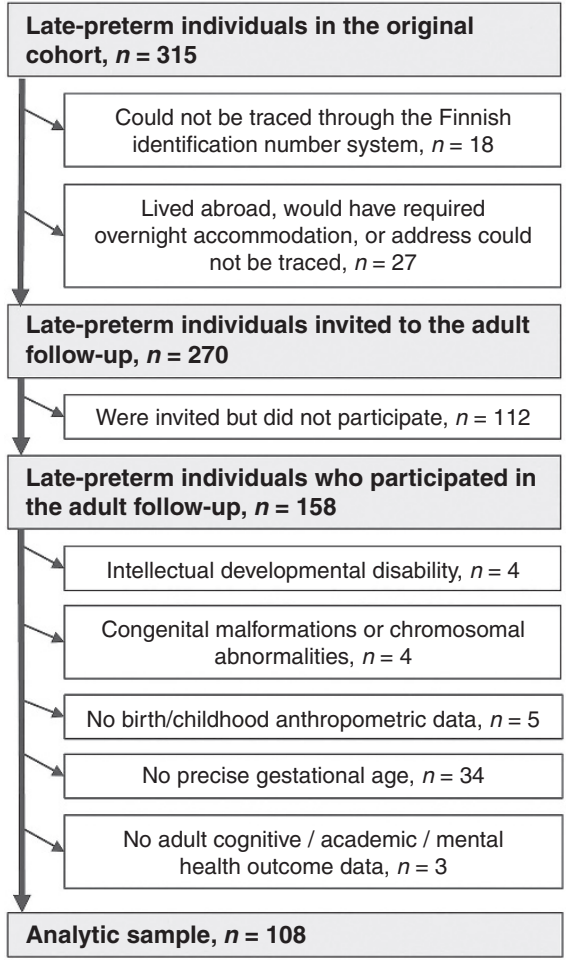

Figure 1. Flowchart of study participation in the late-preterm cohort. $n$ : number of individuals.

in each of the analyses varied according to growth and outcome data availability, as shown in Supplementary Tables S1-S2 online. 101 participants (93.5\% of the analytic sample) had been admitted to a neonatal ward within $10 \mathrm{~d}$ of birth. Based on childhood records and adult self-report, none in the analytic sample had cerebral palsy or visual or hearing impairment.

The childhood study protocol was approved by the Helsinki City Maternity Hospital, Helsinki University Central Hospital, and Jorvi Hospital ethics committees, and the adulthood protocol by the Helsinki and Uusimaa Hospital District Coordinating Ethics Committee. Informed consent was obtained from parents (childhood and adulthood) and participants (adulthood).

\section{Attrition}

To test for selective attrition, we compared the analytic sample $(n=$ 108 ) with the attrition group (those who could not be included because of nonparticipation or missing data, $n=188$ ); we excluded those with intellectual developmental disability $(n=8)$ or congenital malformations or chromosomal abnormalities $(n=11)$ from these comparisons. Between the analytic sample and attrition group, we found no differences in sex, gestational age, parental education, or age at childhood follow-ups; weight, length, or head circumference at birth or childhood follow-ups; maternal age, diabetes, hypertensive disorder, or smoking during pregnancy; parity or multiple pregnancy; or infant Apgar scores, ventilation treatment, septicemia, convulsions, or apnea ( $P$-values $>0.07)$. Compared with the analytic sample, the attrition group had mothers with higher prepregnancy body mass index $(\mathrm{BMI})($ mean $=$ 23.1 vs. $21.8, n=183$ vs. $108, P$-value $=0.002$ ) and received less breastfeeding $(22 \%, 48 \%, 30 \%$ vs. $7 \%, 61 \%, 31 \%$ never breast-fed, breast-feeding discontinued by $5 \mathrm{mo}$, and breast-fed at $5 \mathrm{mo}$, respectively, $n=156$ vs. $108, P$-value $=0.01)$. Compared with the analytic sample, the adult follow-up participants excluded because of missing data $(n=42$, Figure 1) were slightly older at adult follow-up (mean $=25.5$ vs. $25.2 \mathrm{y}, P$-value $=0.048$ ), but we found no differences in neurocognitive, school, or psychiatric outcomes or maternal mental disorder $(P$-values $>0.15)$.

\section{Body Size at Birth, 5 and 20 mo CA, and 56 mo}

Experienced research nurses measured weight, length or height (referred to as length, for simplicity), and head circumference at 5 and
20 mo CA, and 56 mo of chronological age, and we retrieved corresponding birth measurements from medical records. We converted birth sizes into $z$-scores by sex and gestational age, according to Finnish standards (26). Using the World Health Organization growth charts (27), we standardized childhood sizes by sex and CA (5 and $20 \mathrm{mo}$ ) or chronological age (56 mo).

\section{Cognitive, Academic, and Mental Health Outcomes}

We used seven subtests (Information, Similarities, Arithmetic, Digit Span, Picture Completion, Matrix reasoning, and Digit Symbol Coding) of the Wechsler Adult Intelligence Scale-III (28) for estimating Intelligence Quotient (IQ), and three subtests (Logical Memory, Verbal Paired Associates, and Faces) of the Wechsler Memory ScaleIII (29) for estimating General Memory. Phonetic (words beginning with letters $\mathrm{S}$ and $\mathrm{P}$ ) and Categorical (animal, vegetable or fruit names) Verbal fluency (30), The Trail Making Test (31), and The Bohnen version of the Stroop test (32) measured executive functioning. We utilized principal component analysis with Varimax rotation to reduce the executive functioning and attention outcomes into principal components. The first component had an eigenvalue $>1$ and explained $56.9 \%$ of the total variance (see Supplementary Table S3 online), and was named Executive functioning: higher scores reflected better performance in Fluency, Trail Making, and Stroop tests. Participants reported grade point average $(G P A)$ on their final comprehensive school diploma (usually issued the year an individual turns $16 \mathrm{y}$, in Finland), and whether they had received remedial or special education in comprehensive school.

We used M-CIDI interviews (33) in concordance with the Diagnostic and Statistical Manual of Mental Disorders, fourth edition, to diagnose common mental disorders (major depressive disorder, dysthymia, bipolar disorder; general anxiety disorder, social phobia, agoraphobia, panic disorder with or without agoraphobia; and alcohol or other substance use dependence or abuse disorder) within the past $12 \mathrm{mo}$. The participants also completed the ASEBA Adult SelfReport (34), on which the Total Problems score reflects overall psychiatric symptoms and poor psychosocial adjustment, Internalizing Problems subscore reflects symptoms of anxiety, depression, withdrawal, and somatic complaints, and Externalizing Problems subscore reflects delinquent or aggressive behavior symptoms. Higher scores on all scales reflect more frequent or severe symptoms. The interviews and neuropsychological assessments were performed by eight master's level psychology students (incl. S.S.), trained and supervised by clinical psychologists (K.H., J.L., A.-K.P.) and a psychiatrist with WHO authorization (S.P.), blind to all earlier participant information.

\section{Covariates}

Gestational age was based on fetal ultrasound performed before $24+0$ wk' gestation $(n=72)$, or last menstrual period $(n=36)$, independently verified from medical records. From clinical pre and postnatal records, we extracted sex, date of birth for calculating age during visits (d), and pregnancy-related factors (multiple pregnancy (singleton/ multiple), parity (primiparous/multiparous), maternal prepregnancy BMI $\left(\mathrm{kg} / \mathrm{m}^{2}\right)$, age at delivery $(\mathrm{y})$, and hypertensive disorders (normotension/hypertensive disorder), diabetes (no diabetes/gestational or type 1 diabetes; none had type 2 diabetes), and smoking (no/yes, at least one cigarette per day) during pregnancy). Data on neonatal complications, collected during daily ward visits by the pediatricians in the study (incl. A.L.), included 5-min Apgar score ( $>7 / 0-7$ points) and suspected septicemia, ventilation treatment, convulsions, and apnea (each no/yes). Ventilation treatment included continuous positive airway pressure and mechanical ventilation. No participants were diagnosed with intraventricular hemorrhage, necrotizing enterocolitis, or septicemia confirmed by positive blood culture. Highest education of either parent (basic/vocational/general upper secondary and lower tertiary/upper tertiary), and child breast-feeding status at 5 mo CA (never breast-fed/breast-feeding discontinued/currently breastfed) came from parental interviews during childhood. Mothers selfreported history of maternal mental disorder during adult follow-up.

So that missing covariate data would not affect sample size, four participants without 5-min Apgar scores were included in the " $8-10$ points" category based on their high 1- and 10-min Apgar scores and clinical descriptions; eight mothers without mention of blood pressure 
measurements, hypertension, or pre-eclampsia in clinical records were included in the "no hypertensive disorder" group; and 27 mothers who did not report on history of (maternal) mental disorder were considered a separate category when dummy-coding the variable.

\section{Statistical Analyses}

We used linear regression models to test if growth from (i) birth to $5 \mathrm{mo} \mathrm{CA}$, (ii) 5-20 mo CA, and (iii) $20 \mathrm{mo} \mathrm{CA}$ to $56 \mathrm{mo}$ predicted IQ, General memory, Executive functioning, GPA, and Internalizing, Externalizing, and Total psychiatric problems scores; and logistic regression analyses with special education and mental disorders as outcomes. We square-transformed IQ, General memory, GPA, and square-root-transformed psychiatric problems scores, to attain normality, and standardized these outcomes within the sample (mean $=0, \mathrm{SD}=1)$ to facilitate comparison of effect sizes. So that growth period duration or earlier growth would not interfere with the interpretation of results, we used, as growth variables, standardized residual change scores from linear regression models where weight, length, and head circumference $z$-scores were regressed on corresponding measures at previous time points, creating uncorrelated residuals that reflect growth conditional on previous history (19). We considered two-tailed $P$-values $<0.05$ statistically significant.

In Model I, we adjusted for gestational age at birth, sex, age during visits (5 and 20 mo CA, chronological age at 56 mo and in adulthood), and parental education. In Model II, we further adjusted for pregnancy-related factors (listed above, in "Covariates"). In Model III, we adjusted for Model I-II factors, neonatal complications, and breastfeeding status at 5 mo CA. In supplementary analyses with mental health outcomes (Model IV), we reran Model III while further adjusting for maternal mental disorder. In additional analyses, to test if associations between growth and adult neurocognitive, school, or mental health outcomes varied by birth size, we included an interaction term "standardized birth size x corresponding growth measure" into the regression equation followed by main effects. When we observed statistically significant interactions, we divided the sample into thirds by birth size and examined the main effects separately in each group.

\section{RESULTS}

Table 1 shows body size and growth in childhood, Table 2 shows background characteristics and adult outcomes of the late-preterm participants.

\section{Neurocognitive Abilities and School Performance}

We present associations between growth in weight (Figure 2), head circumference (Figure 3), length (Figure 4), and adult neurocognitive abilities and GPA in comprehensive school, among those born late-preterm. Supplementary Table S1 online provides more detailed data on these associations and those between early growth and special education, across adjustment models.

Faster birth-to-5-months' weight and head growth was associated with higher IQ, Executive functioning, and GPA; and faster 5-to-20-months' head growth was associated with higher IQ and GPA. For each SD unit faster growth, these scores increased by $0.19-0.41$ SD units ( $95 \%$ confidence intervals (CI) 0.002-0.59), after adjusting for sex, gestational age, age during visits, and parental education (Model I). Faster growth from birth to 5 mo was also associated with lower odds of receiving special education (Model $\mathrm{I}$ ) (odds ratio $(\mathrm{OR})=0.59,95 \% \mathrm{CI}=$ $0.36-0.97$, and $\mathrm{OR}=0.49,95 \% \mathrm{CI}=0.28-0.88$, per one SD unit faster weight and head growth, respectively).

After adjusting for pregnancy-related factors (Model II), faster birth-to-5-month' weight gain was associated with higher Executive functioning, General memory, and GPA,
Table 1. Body size and growth in childhood in the late-preterm cohort

\begin{tabular}{|c|c|c|}
\hline & $M(S D)$ & Participants \\
\hline \multicolumn{3}{|l|}{ Characteristics at birth } \\
\hline Weight, kg & $2.7(0.6)$ & 108 \\
\hline Length, $\mathrm{cm}$ & $47(2.4)$ & 108 \\
\hline Head circumference, $\mathrm{cm}$ & $33(1.6)$ & 107 \\
\hline \multicolumn{3}{|l|}{ Growth from birth to $5 \mathrm{mo} C A$} \\
\hline Weight, kg & $4.7(0.9)$ & 108 \\
\hline Length, $\mathrm{cm}$ & $19(2.3)$ & 107 \\
\hline Head circumference, cm & $10(1.5)$ & 106 \\
\hline \multicolumn{3}{|c|}{ Characteristics at the 5 -mo visit } \\
\hline Weight, kg & $7.4(0.9)$ & 108 \\
\hline Length, $\mathrm{cm}$ & $66(2.2)$ & 107 \\
\hline Head circumference, cm & $43(1.3)$ & 107 \\
\hline Corrected age, $d$ & $152(11)$ & 108 \\
\hline \multicolumn{3}{|l|}{ Growth from 5 to $20 \mathrm{mo} \mathrm{CA}$} \\
\hline Weight, kg & $4.5(0.9)$ & 103 \\
\hline Length, $\mathrm{cm}$ & $19(2.4)$ & 97 \\
\hline Head circumference, $\mathrm{cm}$ & $5.8(0.7)$ & 100 \\
\hline \multicolumn{3}{|c|}{ Characteristics at the 20 -mo visit } \\
\hline Weight, kg & $12(1.3)$ & 103 \\
\hline Length, $\mathrm{cm}$ & $85(3.2)$ & 98 \\
\hline Head circumference, $\mathrm{cm}$ & $49(1.4)$ & 102 \\
\hline Corrected age, $d$ & $614(16)$ & 106 \\
\hline \multicolumn{3}{|c|}{ Growth from $20 \mathrm{mo} C A$ to $56 \mathrm{mo}$} \\
\hline Weight, kg & $5.9(1.3)$ & 86 \\
\hline Length, $\mathrm{cm}$ & $23(2.4)$ & 79 \\
\hline Head circumference, $\mathrm{cm}$ & $2.8(0.6)$ & 82 \\
\hline \multicolumn{3}{|c|}{ Characteristics at the $56-\mathrm{mo}$ visit } \\
\hline Weight, kg & $18(2.2)$ & 89 \\
\hline Length, $\mathrm{cm}$ & $108(4.3)$ & 86 \\
\hline Head circumference, $\mathrm{cm}$ & $52(1.6)$ & 88 \\
\hline Age, $d$ & $1,721(14)$ & 91 \\
\hline
\end{tabular}

CA, corrected age; cm, centimeters; kg, kilograms; M, mean; participants, number of participants for whom data were available; SD, standard deviation.

and lower odds of special education; birth-to-5-months' head growth was associated with higher GPA and lower odds of special education; and 5-to-20-months' head growth was associated with higher IQ and GPA (effect sizes $0.22-0.43$, 95\% CI's 0.01-0.62; OR's $0.53-0.54$, 95\% CI 0.28-0.99). After further adjusting for neonatal factors (Model III), faster birth-to-5-months' weight growth was associated with higher Executive functioning and GPA; birth-to-5-months' head growth with higher Executive functioning and GPA, and lower odds of special education; and 5-to-20-months' head growth with higher IQ and GPA (effect sizes $0.23-0.42,95 \%$ CI's $0.002-0.62$; OR $0.46,95 \%$ CI $0.22-0.94$ ). Although rendered below the conventional level of significance in models II and/or III, in effect size the associations between birth-to5-months' weight gain, IQ, and special education, and birthto-5-months' head growth, IQ, and Executive functioning changed only a little (difference in effect sizes ranged between 0.03-0.05 SD units, between significant and further adjusted 


\section{Articles | Sammallahti et al.}

Table 2. Background characteristics and adult outcomes of the late-preterm participants

\begin{tabular}{|c|c|c|c|}
\hline & $n(\%)$ & $\mathrm{M}(\mathrm{SD})$ & Participants \\
\hline \multicolumn{4}{|l|}{ Background characteristics } \\
\hline Male & $62(57)$ & & 108 \\
\hline Gestational age in days & & $250(6)$ & 108 \\
\hline Highest education level of either parent & & & 108 \\
\hline Basic education & $11(10)$ & & \\
\hline Vocational education & $27(25)$ & & \\
\hline Higher tertiary education & $33(31)$ & & \\
\hline Age at follow-up in years & & $25.2(0.6)$ & 108 \\
\hline \multicolumn{4}{|l|}{ Pregnancy-related factors } \\
\hline Singleton & $91(84)$ & & 108 \\
\hline First-born & $64(59)$ & & 108 \\
\hline Maternal diabetes during pregnancy & $12(11)$ & & 108 \\
\hline Maternal hypertensive disorder during pregnancy & $25(25)$ & & 100 \\
\hline \multicolumn{4}{|l|}{ Neonatal complications and breast-feeding } \\
\hline Apgar score at $5 \mathrm{~min}<8$ points & $7(7)$ & & 104 \\
\hline Received ventilation treatment & $8(7)$ & & 108 \\
\hline Suspicion of septicemia & $18(17)$ & & 108 \\
\hline Convulsions & $3(3)$ & & 108 \\
\hline Apnea & $3(3)$ & & 108 \\
\hline Breast-feeding status at 5 mo corrected age & & & 108 \\
\hline Never breast-fed & $8(7)$ & & \\
\hline \multicolumn{4}{|l|}{ Maternal mental disorder } \\
\hline General memory score & & $103(13)$ & 105 \\
\hline Trail Making Test part A, $\mathrm{s}^{\mathrm{b}}$ & & $31(10)$ & 104 \\
\hline Trail Making Test part $\mathrm{B}, \mathrm{s}^{\mathrm{b}}$ & & $60(17)$ & 104 \\
\hline Fluency, phonetic task raw score ${ }^{b}$ & & $17(4.6)$ & 105 \\
\hline Fluency, categorical task raw score ${ }^{b}$ & & $23(5.6)$ & 105 \\
\hline Stroop, baseline task, $\mathrm{s}^{\mathrm{b}}$ & & $68(15)$ & 102 \\
\hline Stroop, interference task, $\mathrm{s}^{\mathrm{b}}$ & & $120(29)$ & 102 \\
\hline \multicolumn{4}{|l|}{ Comprehensive school performance } \\
\hline Grade point average, scale of $4-10$ & & $8.2(0.9)$ & 92 \\
\hline Received special education & $35(35)$ & & 101 \\
\hline \multicolumn{4}{|l|}{ Self-reported psychosocial adjustment } \\
\hline Internalizing problems T-score & & $44(12)$ & 89 \\
\hline Externalizing problems T-score & & $47(9.0)$ & 89 \\
\hline Total problems T-score & & $44(11)$ & 89 \\
\hline \multicolumn{4}{|l|}{ Psychiatric interview } \\
\hline Diagnosis of common mental disorder ${ }^{c}$ & $34(35)$ & & 98 \\
\hline
\end{tabular}

af the 14 mothers who reported mental health problems, 11 reported depression and 3 reported an anxiety disorder; none reported other psychiatric disorders. ${ }^{b}$ All these executive functioning test scores were available for 101 late-preterm individuals, whom we thus included in the principal component analysis. 'Of the 34 late-preterm participants diagnosed with at least one mental disorder, 14 were diagnosed with mood disorder, 8 with anxiety disorder, and 25 with substance use disorder.

BMI, Body-Mass-Index, kilograms per square meter; M, mean; n, number of participants; Participants, number of participants for whom data were available; $\mathrm{S}$, seconds; SD, standard deviation. 
nonsignificant models; the OR which was rendered nonsignificant decreased by 0.06 ).

We found no statistically significant associations between any neurocognitive or school outcomes and length growth, weight gain after $5 \mathrm{mo}$, or head growth after 20 mo ( $P$-values $>0.12$, Model I).

\section{Psychiatric Disorders and Problems}

Supplementary Table S2 online presents the associations between growth and mental health outcomes. Faster head growth from 20 to 56 mo was associated with lower Internalizing and Total problems scores in Model I (effect sizes -0.30 and $-0.28 \mathrm{SD}$, respectively, for every one SD faster growth, $95 \%$ CI -0.56 to -0.02 ), and Model II (effect sizes -0.34 and -0.33 SD, respectively, $95 \%$ CI's -0.63 to -0.04 ; also associated with lower Externalizing scores, effect size -0.32 SD, $95 \%$ CI -0.62 to -0.01$)$. These associations were nonsignificant in Model III (effect sizes -0.26 and -0.27 SD, 95\% CI's -0.57 to 0.02 ), but reached statistical significance again after further adjusting for maternal mental disorder (Model IV) (effect sizes -0.30 and -0.33 SD, 95\% CI's -0.66 to -0.004 ). No other associations between growth and psychiatric disorders or problems were consistently significant across different adjustment models ( $P$-values $>0.09$ in Model I).

\section{Interactions between Birth Size and Growth}

We found interactions between birth head circumference and head growth from birth to $5 \mathrm{mo}$, when examining GPA and General memory $(P$-values for interactions $P=0.023$ and 0.042 , respectively). Faster birth-to-5-months' head growth was associated with higher GPA among those with the largest birth head circumference, i.e., highest third (effect size 0.56 SD, 95\% CI $0.08-1.04$ ) (head circumference $>0.5 \mathrm{SD}$ in this group, $n=31$ ), but not in the middle third (effect size 0.34 SD, $95 \%$ CI $-0.04-$ 0.73 ) (head circumference -0.2 to $0.5 \mathrm{SD}, n=31$ ) or lowest third (effect size 0.27 SD, 95\% CI -0.12-0.67) (head circumference $<-0.2 \mathrm{SD}, n=29)$. General memory was not associated with birth-to-5-months' head growth in any tertile group ( $P$-values $>0.11)$. There were no other statistically significant interactions between birth size and childhood growth (model I).

\section{DISCUSSION}

In this study, in a cohort of 108 late-preterm individuals followed up to adulthood, we showed that faster growth in weight and head circumference from birth to 5 mo CA was associated with higher IQ and better executive functioning in adulthood, higher GPA at the end of comprehensive school, and lower odds of having received special education in comprehensive school. Those who showed faster head growth from 5 to 20 mo CA also had higher adult IQ and GPA, but growth after early infancy was otherwise not associated with neurocognitive or school outcomes. Our results also suggested that faster head growth from 20 to 56 mo may be associated with fewer self-reported internalizing problems; otherwise, we found no consistent associations between growth and mental health outcomes, or growth in length and any of the studied outcomes. a

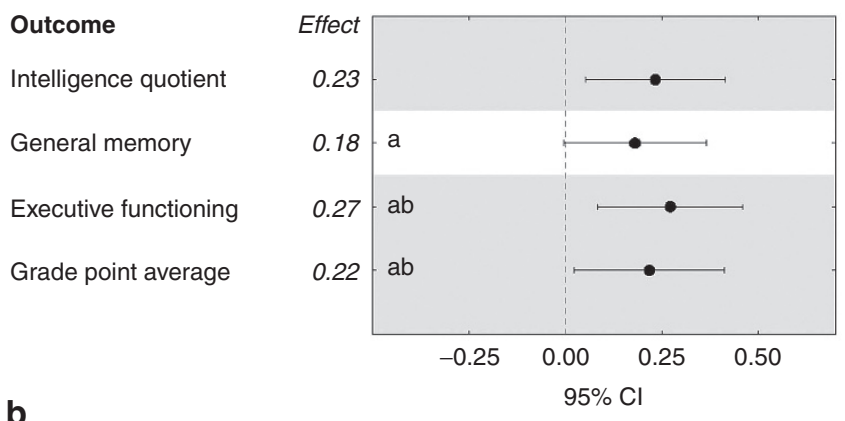

b

Outcome

Intelligence quotient

General memory

Executive functioning

Grade point average

C

\section{Outcome}

Intelligence quotient

General memory

Executive functioning

Grade point average
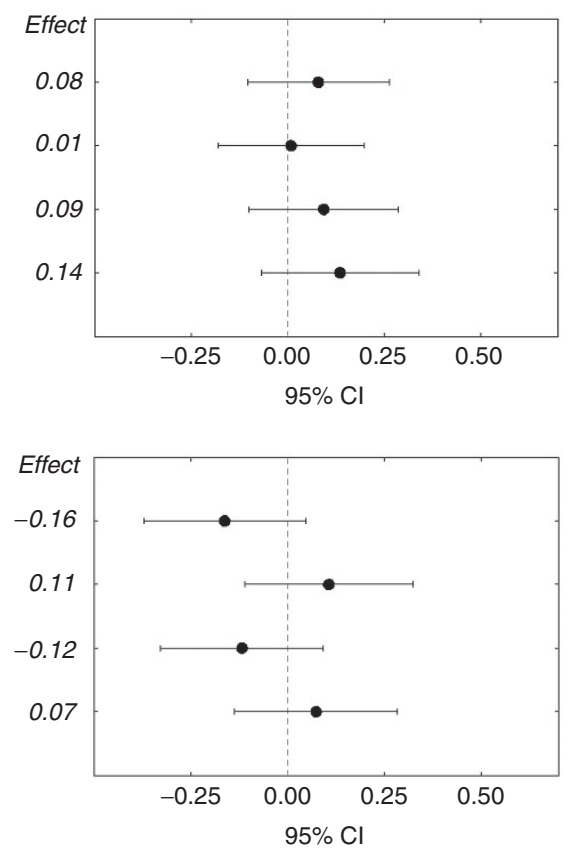

Figure 2. Growth in weight in childhood after late-preterm birth, adult neurocognitive abilities, and grade point average in comprehensive school. (a) Growth in weight from birth to 5 mo corrected age. (b) Growth in weight from 5 to 20 mo corrected age. (c) Growth in weight from 20 mo corrected age to $56 \mathrm{mo}$. The figure shows change in adult neurocognitive composite scores and grade point average in standard deviation units, per one standard deviation unit faster growth in weight during the time period in question. The growth variables are standardized residual change scores from linear regression models where weight $z$-scores were regressed on measures at previous time points, creating uncorrelated residuals that reflect growth conditional on previous history. We adjusted for gestational age, sex, age at follow-up visit, and highest education of a parent in all analyses. Statistically significant associations $(P<0.05)$ highlighted. a $P<$ 0.05 in model II (after additional adjustments for multiple pregnancy, parity, and maternal smoking, hypertension, and diabetes during pregnancy, prepregnancy body-mass-index, and age at delivery). ${ }^{\mathrm{b}} P<0.05$ in model III (after further adjusting also for breast-feeding status at 5 mo and neonatal complications including low Apgar score, apnea, convulsions, suspected septicemia, and ventilation treatment). $\mathrm{Cl}$, confidence interval.

For every one SD faster weight or head growth, our study participants scored 0.19-0.41 SD units higher in estimated IQ, executive functioning, and GPA, and had lower odds (OR 0.49-0.59) of having received special education. The pattern of findings, including effect sizes of the significant associations, corresponds to those previously reported for very-low-birthweight preterm individuals (who scored 0.23-0.43 SD units 


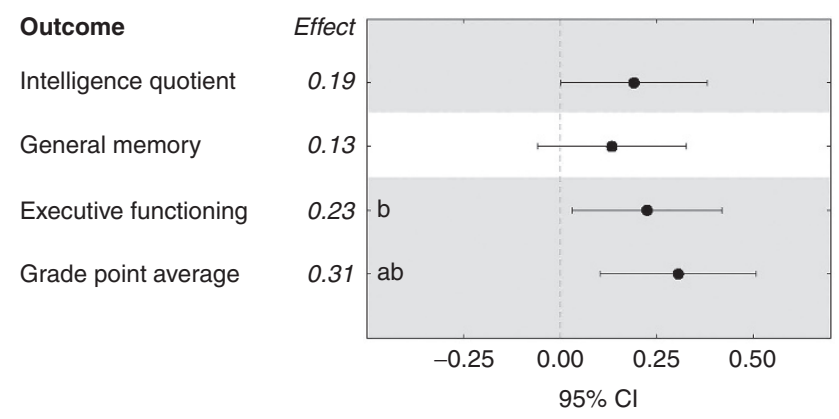

b

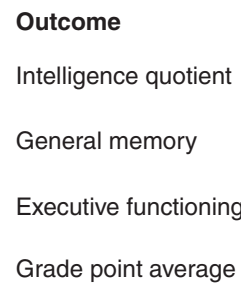

C

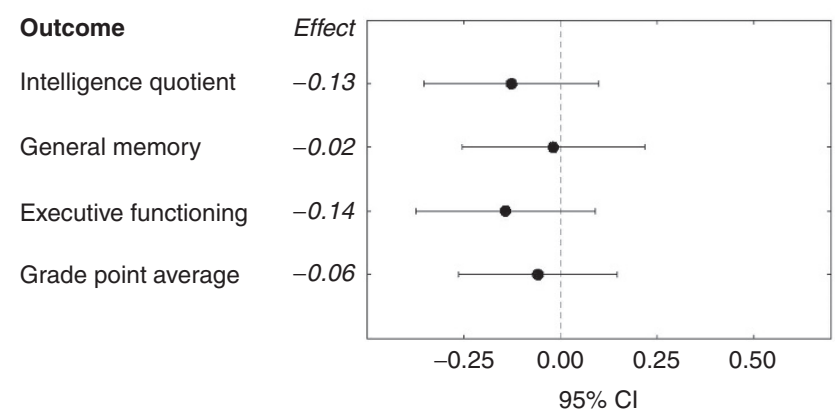

Figure 3. Growth in head circumference in childhood after late-preterm birth, adult neurocognitive abilities and grade point average in comprehensive school. (a) Growth in head circumference from birth to 5 mo corrected age. (b) Growth in head circumference from 5 to 20 mo corrected age. (c) Growth in head circumference from 20 mo corrected age to 56 mo. The figure shows change in adult neurocognitive composite scores and grade point average in standard deviation units, per one standard deviation unit faster growth in head circumference during the time period in question. The growth variables are standardized residual change scores from linear regression models where head circumference $z$-scores were regressed on measures at previous time points, creating uncorrelated residuals that reflect growth conditional on previous history. We adjusted for gestational age, sex, age at follow-up visit, and highest education of a parent in all analyses. Statistically significant associations $(P<0.05)$ highlighted. ${ }^{a} P<0.05$ in model II (after additional adjustments for multiple pregnancy, parity, and maternal smoking, hypertension, and diabetes during pregnancy, prepregnancy body-mass-index, and age at delivery). ${ }^{\mathrm{b}} P<0.05$ in model III (after further adjusting also for breast-feeding status at 5 mo and neonatal complications including low Apgar score, apnea, convulsions, suspected septicemia, and ventilation treatment). $\mathrm{Cl}$, confidence interval.

higher in neurocognitive tests, per one SD faster growth from birth to term-equivalent-age, particularly in head circumference) $(19,35)$.

To our knowledge, our study is the first to examine growth after late-preterm birth in relation to any of these outcomes. These results are mainly in line with most - but not all (23-25) a

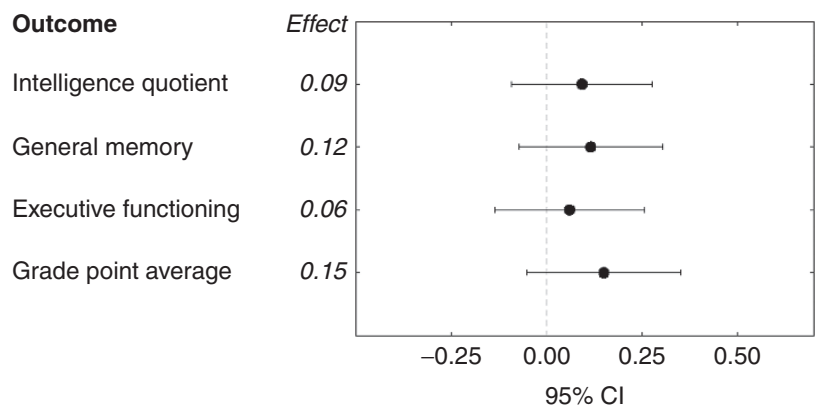

b

Outcome
Intelligence quotient
General memory
Executive functioning
Grade point average

C

Outcome
Intelligence quotient
General memory
Executive functioning
Grade point average
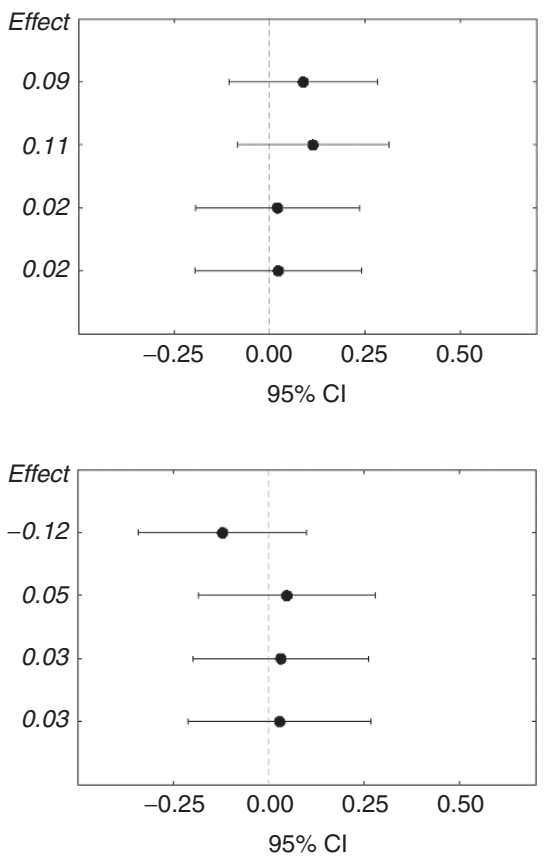

Figure 4. Growth in length in childhood after late-preterm birth, adult neurocognitive abilities and grade point average in comprehensive school. (a) Growth in length from birth to 5 mo corrected age. (b) Growth in length from 5 to 20 mo corrected age. (c) Growth in length from 20 mo corrected age to $56 \mathrm{mo}$. The figure shows change in adult neurocognitive composite scores and grade point average in standard deviation units, per one standard deviation unit faster growth in length during the time period in question. The growth variables are standardized residual change scores from linear regression models where length $z$-scores were regressed on measures at previous time points, creating uncorrelated residuals that reflect growth conditional on previous history. We adjusted for gestational age, sex, age at follow-up visit, and highest education of a parent in all analyses. There were no statistically significant associations $(P<0.05)$ in model I, model II (after additional adjustments for multiple pregnancy, parity, and maternal smoking, hypertension, and diabetes during pregnancy, prepregnancy body-mass-index, and age at delivery). or model III (after further adjusting also for breast-feeding status at $5 \mathrm{mo}$ and neonatal complications including low Apgar score, apnea, convulsions, suspected septicemia, and ventilation treatment). $\mathrm{Cl}$, confidence interval.

- previous studies, which suggest that faster growth soon after being born very-preterm (9-12,36), early-preterm (13), preterm (14), or preterm with extremely low (15-18) or very low (9,10,19-22) birth weight may benefit neurodevelopment (9-22) and academic achievement $(11,12,14,17,36)$, but not so much mental health $(14,17,25,35)$. This study also supports the notion that mechanisms underlying preterm birth and neurocognitive 
vulnerability are at least partly different from those underlying preterm birth and mental health risk (37).

Our findings were not explained by manifest developmental disability or congenital malformations, as participants with these conditions were excluded, or by variation in gestational age or socio-economic background. The associations between faster growth and better neurodevelopment were also independent of earlier growth and no more pronounced in those with smaller birth size, indicating that environmental factors during the growth period, rather than catch-up growth after previous growth restriction, underlay the associations. Moreover, adjustment for a range of pregnancy-related and neonatal conditions produced only small changes in the regression coefficients, indicating that the reported associations were not explained by common manifest pregnancy or neonatal disorders, but were more likely to reflect a multitude of environmental conditions during the growth period.

While the mechanisms underlying these associations remain largely unknown, our results highlight the importance of the early period after late-preterm birth for neurodevelopment. At $34 \mathrm{wk}$ gestation, the earliest limit of late-preterm birth, cortical volume is only $53 \%$ and total brain volume $65 \%$ of the term brain, and major structural maturation is yet to occur (38). The interruption of development in the normal protective intrauterine environment during this vulnerable period may alter brain maturation and growth through interplay of inadequate nutrition, damage to developing organs, increased risk of infection and other neonatal complications. It has been suggested that late-preterm infants could benefit from more careful consideration of individual nutritional needs (39) and of susceptibility to complications (3), for example, but direct evidence from intervention studies aimed at improving longterm neurodevelopment after late-preterm birth is lacking. It is also worth noting that while the 12 -mo prevalence rates of substance use, mood, and anxiety disorders in our cohort $(26,14$, and $8 \%$ of those who underwent psychiatric interview, respectively; $35 \%$ had at least one of these mental disorders) may seem striking, they are not characteristic of the late-preterm population in particular (8), but rather reflect the high prevalence of mental disorders among young people (40), underlining the urgent need to identify early risk factors for mental disorders.

Our study strengths include the long follow-up of latepreterm individuals to adulthood, validated and extensive outcome data, conditional growth modeling methods, and detailed pre- and postnatal data. The main limitation of our study is the loss of follow-up. Of the original 315 latepreterm individuals, 270 could be traced and were invited. Of those invited, 158 (59\%) participated in the adult followup. After excluding those whose gestational age, childhood anthropometry and long-term outcomes could not be reliably determined, and those whose developmental disabilities, congenital malformations or chromosomal abnormalities could have affected growth and neurodevelopment, 108 participants were included in the analytic sample (34\% of original cohort and $68 \%$ of the participants of the adult-follow-up). The rate of attrition, while not exceptional for similar long-term follow-up studies which require active participation (41) calls for caution in interpreting the results. Even though those whom we excluded from the study because of missing data did not greatly differ from the analytic sample, loss of follow-up may cause selection bias and impact generalizability of the results, especially into less healthy groups. The direction, size and confidence intervals of the reported effects did not suggest any systematic associations between growth and mental health, or growth after $20 \mathrm{mo}$ and neurodevelopment: while this is in line with previous studies, not finding associations do not mean that they cannot exist. Our findings encourage future studies to test these associations in larger samples, to detect potential small or, even more importantly, subgroup specific effects that were beyond the scope of this study. Other limitations include possible residual confounding. Further, study participants, born in 1985-1986, may not be representative of late-preterm infants born today, and we could not address more rare mental disorders such as schizophrenia, life-long prevalence of mental disorders, or final achieved educational level.

To alter the trajectory of cognitive development, early intervention is important (42). Even though those late-preterm individuals of our cohort who grew more slowly in infancy were more likely to receive additional support in school age, they still reported poorer grades at the end of comprehensive school and showed lower general intelligence and executive abilities as adults, compared with faster-growing late-preterm peers. Future research may show whether, during this critical time period, targeted interventions could compensate for the long-lasting risks associated with late-preterm birth.

\section{SUPPLEMENTARY MATERIAL}

Supplementary material is linked to the online version of the paper at http:// www.nature.com/pr

\section{ACKNOWLEDGMENTS}

We thank Juha Peltola and Anja Niemelä and research nurse Paula Nyholm along with numerous others for data collection, and Vili Heinonen for help with Python.

\section{STATEMENT OF FINANCIAL SUPPORT}

Study baseline and childhood follow-up was financially supported by the Bundesministerium für Forschung und Technik (Federal Government of Germany, Ministry of Science and Technology) program grants PKE 4 and JUG 14 (FKZ's 0706224, 0706564, and 01EP9504) to Klaus Riegel, Dieter Wolke, and Barbara Ohrt. The work by Lano was supported by Foundation of Pediatric Research. Adulthood follow-up was financially supported by the Academy of Finland program grants to Eriksson, Raikkonen, and Kajantie. The work by Heinonen, M. Lahti, J. Lahti, and Pesonen was supported by Academy of Finland postdoctoral grants. The work by S. Sammallahti was supported by the University of Helsinki Research Fund. Eriksson was supported also by grant from Samfundet Folkhälsan and Andersson from Päivikki and Sakari Sohlberg Foundation and Finska Läkaresällskapet. The funding sources took no part in the design of the study, the collection, analysis, interpretation, or reporting of the data, or the decision to submit the manuscript for publication.

Disclosure: The authors have no conflicts of interests to disclose. 


\section{Articles $\quad$ Sammallahti et al.}

\section{REFERENCES}

1. March of Dimes, PMNCH, Save the Children WHO. In: Howson C, Kinney M, Lawn J, editors. Born Too Soon: The Global Action Report on Preterm Birth. Geneva: World Health Organization; 2012.

2. Blencowe H, Cousens S, Oestergaard MZ, et al. National, regional, and worldwide estimates of preterm birth rates in the year 2010 with time trends since 1990 for selected countries: a systematic analysis and implications. Lancet 2012;379:2162-72.

3. Raju TN, Higgins RD, Stark AR, Leveno KJ. Optimizing care and outcome for late-preterm (near-term) infants: a summary of the workshop sponsored by the National Institute of Child Health and Human Development. Pediatrics 2006;118:1207-14.

4. Saigal S, Doyle LW. An overview of mortality and sequelae of preterm birth from infancy to adulthood. Lancet 2008;371:261-9.

5. Santos IS, Matijasevich A, Domingues MR, Barros AJ, Victora CG, Barros FC. Late preterm birth is a risk factor for growth faltering in early childhood: a cohort study. BMC Pediatr 2009;9:71.

6. Heinonen K, Eriksson JG, Lahti J, et al. Late preterm birth and neurocognitive performance in late adulthood: a birth cohort study. Pediatrics 2015;135:e818-25.

7. Heinonen K, Eriksson JG, Kajantie E, et al. Late-preterm birth and lifetime socioeconomic attainments: the Helsinki birth cohort study. Pediatrics 2013;132:647-55.

8. Heinonen K, Kajantie E, Pesonen AK, et al. Common mental disorders in young adults born late-preterm. Psychol Med 2016;46:2227-38.

9. Weisglas-Kuperus N, Hille ETM, Duivenvoorden HJ, Finken MJJ, Wit JM, van Buuren S, et al. Intelligence of very preterm or very low birthweight infants in young adulthood. Arch Dis Child - Fetal Neonatal Ed. 2009;94(3):F196-200.

10. Leppänen M, Lapinleimu H, Lind A, et al.; PIPARI Study Group. Antenatal and postnatal growth and 5-year cognitive outcome in very preterm infants. Pediatrics 2014;133:63-70.

11. Kan E, Roberts G, Anderson PJ, Doyle LW; Victorian Infant Collaborative Study Group. The association of growth impairment with neurodevelopmental outcome at eight years of age in very preterm children. Early Hum Dev 2008;84:409-16.

12. Cooke RW, Foulder-Hughes L. Growth impairment in the very preterm and cognitive and motor performance at 7 years. Arch Dis Child 2003;88:482-7.

13. Belfort MB, Rifas-Shiman SL, Sullivan T, et al. Infant growth before and after term: effects on neurodevelopment in preterm infants. Pediatrics 2011;128:e899-906.

14. Casey PH, Whiteside-Mansell L, Barrett K, Bradley RH, Gargus R. Impact of prenatal and/or postnatal growth problems in low birth weight preterm infants on school-age outcomes: an 8-year longitudinal evaluation. Pediatrics 2006;118:1078-86.

15. Ehrenkranz RA, Dusick AM, Vohr BR, Wright LL, Wrage LA, Poole WK. Growth in the neonatal intensive care unit influences neurodevelopmental and growth outcomes of extremely low birth weight infants. Pediatrics 2006;117:1253-61.

16. Claas MJ, de Vries LS, Koopman C, et al. Postnatal growth of preterm born children $\leq 750 \mathrm{~g}$ at birth. Early Hum Dev 2011;87:495-507.

17. Stathis SL, O'Callaghan M, Harvey J, Rogers Y. Head circumference in ELBW babies is associated with learning difficulties and cognition but not ADHD in the school-aged child. Dev Med Child Neurol 1999;41:375-80.

18. Sices L, Wilson-Costello D, Minich N, Friedman H, Hack M. Postdischarge growth failure among extremely low birth weight infants: Correlates and consequences. Paediatr Child Health 2007;12:22-8.

19. Sammallahti S, Pyhälä R, Lahti $M$, et al. Infant growth after preterm birth and neurocognitive abilities in young adulthood. J Pediatr 2014;165: 1109-1115.e3.

20. Brandt I, Sticker EJ, Lentze MJ. Catch-up growth of head circumference of very low birth weight, small for gestational age preterm infants and mental development to adulthood. J Pediatr 2003;142:463-8.
21. Nash A, Dunn M, Asztalos E, Corey M, Mulvihill-Jory B, O’Connor DL. Pattern of growth of very low birth weight preterm infants, assessed using the WHO Growth Standards, is associated with neurodevelopment. Appl Physiol Nutr Metab 2011;36:562-9.

22. Franz AR, Pohlandt F, Bode H, et al. Intrauterine, early neonatal, and postdischarge growth and neurodevelopmental outcome at 5.4 years in extremely preterm infants after intensive neonatal nutritional support. Pediatrics 2009;123:e101-9.

23. Cooke RWI. Are there critical periods for brain growth in children born preterm? Arch Dis Child Fetal Neonatal Ed. 2006;91:F17-20.

24. Brandt I, Sticker EJ, Gausche R, Lentze MJ. Catch-up growth of supine length/height of very low birth weight, small for gestational age preterm infants to adulthood. J Pediatr 2005;147:662-8.

25. Huang C, Martorell R, Ren A, Li Z. Cognition and behavioural development in early childhood: the role of birth weight and postnatal growth. Int J Epidemiol 2013;42:160-71.

26. Pihkala J, Hakala T, Voutilainen P, Raivio K. [Characteristic of recent fetal growth curves in Finland]. Duodecim 1989;105:1540-6.

27. WHO Multicentre Growth Reference Study Group. WHO Child Growth Standards: Growth Velocity Based on Weight, Length and Head Circumference: Methods and Development. Geneva: World Health Organization; 2009.

28. Wechsler D. Wechsler Adult Intelligence Scale 3rd edition (WAIS-III), Finnish Version. Helsinki, Finland: Psykologien Kustannus Oy; 2005.

29. Wechsler D. Wechsler Memory Scale 3rd edition (WMS-III), Finnish Version. 3rd ed. Helsinki, Finland: Psykologien Kustannus Oy; 2008.

30. Lezak MD. Neuropsychological Assessment. New York: Oxford University Press; 2004.

31. Reitan RM. Validity of the Trail Making Test as an indicator of organic brain damage. Perceptual and Motor Skills. 1958;8:271-6.

32. Bohnen N, Jolles J, Twijnstra A. Modification of the Stroop Color Word Test improves differentiation between patients with mild head injury and matched controls. Clin Neuropsychol. 1992;6:178-84.

33. Wittchen H-U, Pfister H. DIA-X-Interviews: Manual Für Screening-Verfahren Und Interview; Interviewheft Längsschnittuntersuchung (DIA-XLifetime); Ergänzungsheft (DIAX- Lifetime); Interviewheft Querschnittuntersuchung (DIA-X-12 Monate); Ergänzungsheft (DIA-X-12 Monate); PC-Program. Frankfurt: Swets and Zeitlinger; 1997.

34. Achenbach TM, Rescorla LA. Manual for the ASEBA adult forms \& profiles. Burlington, VT: University of Vermont, Research Center for Children, Youth \& Families; 2003.

35. Sammallahti S, Lahti M, Pyhälä R, et al. Infant growth after preterm birth and mental health in young adulthood. PLoS One 2015;10:e137092.

36. Johnson S, Wolke D, Hennessy E, Marlow N. Educational outcomes in extremely preterm children: neuropsychological correlates and predictors of attainment. Dev Neuropsychol 2011;36:74-95.

37. D'Onofrio BM, Class QA, Rickert ME, Larsson H, Långström N, Lichtenstein P. Preterm birth and mortality and morbidity: a population-based quasi-experimental study. JAMA Psychiatry 2013;70:1231-40.

38. Kinney HC. The near-term (late preterm) human brain and risk for periventricular leukomalacia: a review. Semin Perinatol 2006;30:81-8.

39. Lapillonne A, O'Connor DL, Wang D, Rigo J. Nutritional recommendations for the late-preterm infant and the preterm infant after hospital discharge. J Pediatr 2013;162(3 Suppl):S90-100.

40. Blanco C, Okuda M, Wright C, et al. Mental health of college students and their non-college-attending peers: results from the National Epidemiologic Study on Alcohol and Related Conditions. Arch Gen Psychiatry 2008;65:1429-37.

41. Fewtrell MS, Kennedy K, Singhal A, et al. How much loss to follow-up is acceptable in long-term randomised trials and prospective studies? Arch Dis Child 2008;93:458-61.

42. Doyle O, Harmon CP, Heckman JJ, Tremblay RE. Investing in early human development: timing and economic efficiency. Econ Hum Biol 2009; 7:1-6. 